22 Crichton, J. Defining high, medium, and low security in forensic mental healthcare: the development of the matrix of security in Scotland. J Forensic Psychiatry Psychol 2009; 20: 333-53.

23 McClean RJ. Assessing the security needs of patients in medium secure psychiatric care in Northern Ireland. Psychiatrist 2010; 34: 432-6.

24 Collins M, Davies S. Measuring security needs: a multidimensional approach. In Essential Writings in Violence Risk Assessment (eds C Webster, H Bloom): 553-73. The Centre for Addiction and Mental Health, 2007.
25 Social Work Department. The Forensic Directory (4th edn): National Health and Private Forensic Psychiatric Facilities in the United Kingdom. Rampton Hospital Authority, 1999.

26 Dickens G, Sugarman P, Walker L. HoNOS-secure: a reliable outcome measure for users of secure and forensic mental health services. J Forensic Psychiatry Psychol 2007; 18: 507-14.

27 Royal College of Psychiatrists. HoNOS-secure. Royal College of Psychiatrists, no date (http://www.rcpsych.ac.uk/training/honos/ secure.aspx).

\title{
Penetration of Time to Change leaflets on stigmatised attitudes to people with mental illness
}

\author{
Vania Mendes, ${ }^{1}$ Joby Maducolil Easow, ${ }^{2}$ Jason Luty ${ }^{2,3}$
}

The Psychiatrist (2012), 36, 371-374, doi: 10.1192/pb.bp.110.033795

${ }^{1}$ Institute of Psychiatry, London; ${ }^{2}$ South Essex Partnership NHS Trust, Southend on Sea; ${ }^{3}$ Cambridge \& Peterborough Mental Health NHS Trust, Cambridge

Correspondence to Jason Luty (jason.luty@yahoo.co.uk)

First received 10 Dec 2010, final revision 22 Feb 2012, accepted 15 Mar 2012
Aims and method To determine whether members of the general public read a leaflet from the Time to Change anti-stigma campaign. The leaflets were sent to 1000 members of the public at random. Those who read the leaflet were asked, in a statement concealed within the text, to return it. A second study involved modified leaflets being posted to 400 members of a representative panel of the UK general public.

Results Only 20 of the 1000 (2\%) people who received the unsolicited leaflet returned them, which suggests that the vast majority were unread. However, the leaflet achieved a good response in the sample from the research panel with at least $29 \%$ of participants (115 of 400 ) reading the leaflet.

Clinical implications A very small proportion of people acknowledge unsolicited leaflets. However, the leaflet was read by almost a third of a research panel. Hence, few people are likely to read unsolicited leaflets, including those containing a public health message.

Declaration of interest None.
Stigma is a social construction that devalues people as a result of a distinguishing characteristic or mark. ${ }^{1}$ The World Health Organization (WHO) and World Psychiatric Association (WPA) recognise that the stigma attached to mental disorders is strongly associated with suffering, disability and poverty. ${ }^{2,3}$ Many studies show that negative attitudes towards the mentally ill are widespread and the media generally depicts mentally ill people as violent, erratic and dangerous. ${ }^{4,5}$ Providing factual information in brief fact sheets ${ }^{6,7}$ or through extensive interventions such as educational courses is reported to reduce stigma. $^{8-10}$ These methods have been the basis of several anti-stigma campaigns. ${ }^{5,11}$ In the past few years national anti-stigma campaigns have been launched in Scotland (www.seemescotland.org.uk) and England (www.time-tochange.org.uk). Unfortunately, there have been reports that these campaigns are not particularly effective. ${ }^{12-15}$ These reports discuss the disappointing results to date from the 'Defeat Depression' campaign, the 'Changing Minds' campaign and the Scottish 'See Me' campaign. The aim of the current study was: (a) to determine whether members of the general public read unsolicited promotional literature from the English Time to Change anti-stigma campaign; and (b) how much of any leaflet were they likely to read. The objective was not to determine the effectiveness of the anti-stigma message in the leaflet, although participants' attitudes towards people with mental illness were assessed.

\section{Method}

Two projects took place. Both used modified versions of the 700-word double-sided anti-stigma leaflet entitled 'Lets end mental health discrimination' from the Time to Change campaign. ${ }^{16}$ 


\section{Study one}

The first study aimed to determine whether members of the general public read the unsolicited leaflet. Modified leaflets were sent to 1000 members of the British public at random selected entirely for this study using the wildcard function of the BT online telephone directory. The modified leaflet had an additional line along one lower border offering participants $£ 4$ if they returned the leaflet in the freepost envelope that was enclosed.

\section{Study two}

The second study aimed to determine how much of the leaflet was read by those who chose to look at it. The Time to Change leaflet was posted to individuals from a panel of 400 participants from a previous study recruited using direct mail-shots and adverts in local newspapers as described previously. ${ }^{17}$ Participants also received a questionnaire from a completely separate study. The questionnaire had the following instructions: 'We enclose a leaflet describing the Time to Change campaign for your information'. Four versions of the Time to Change leaflet were generated with the following statement concealed within the text: 'If you have read this far please tick inside the brackets ( ).' (This will be referred to as the 'return-tosender' statement hereafter.) Participants were then asked to return the leaflet in an enclosed freepost envelope. The return-to-sender statement was introduced at 100 words, 250 words, 440 words and 611 words (equal numbers of copies of each version were produced and one was sent at random to each of the participants). The accompanying questionnaire also asked: 'What proportion of people are affected by mental health problems? (a) 1 in 2, (b) 1 in 3, (c) 1 in 4, (d) 1 in 5, (e) 1 in 6' (the leaflet states that mental health problems affect 1 in 4 people). The accompanying questionnaire also included the five-item self-completion

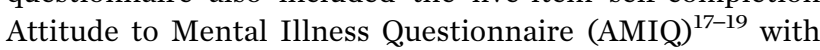
the following vignette: 'Tim is depressed and took a paracetamol overdose last month to try and hurt himself.'

\section{Results}

In study one, only 20 of the $1000(2 \%)$ people who received unsolicited leaflets returned these. This suggests that the vast majority of unsolicited Time to Change leaflets were unread.

In study two, questionnaires were received back from 187 participants of the 400 members of the research panel. In total 115 also returned the Time to Change leaflet to indicate that they had read this (penetration $29 \%$ of the 400 panel members). The mean age of people who returned the questionnaire was 51 years (s.e. $=1.8$ ), $46 \%$ were male and $59 \%$ in paid employment. Over $90 \%$ described their ethnic group as White British.

It made no difference where the return-to-sender statement was placed in the leaflet (27 of the respondents returned the leaflet with the return-to-sender instructions concealed at 100 words; 29 at 250 words; 29 at 440 words and 30 at 611 words - in total 100 versions of each leaflet were distributed).
In total, 115 of 187 participants (61.5\%) who returned the questionnaire correctly endorsed that one in four people will have a mental illness during their lifetime. By contrast $15 \%$ endorsed one in three; $15 \%$ one in five and $12 \%$ one in six. The leaflet contained the information that one in four people will be affected by a mental illness. However, $59 \%$ of the 115 participants who in addition to completing the questionnaire also returned the leaflet endorsed the correct response compared with $52 \%$ of the 72 who did not also return the leaflet. There was therefore no statistically significant difference $(P=0.81)$.

The mean AMIQ stigma score was +1.00 (s.e. $=0.22$, median $1, \mathrm{IQR}=-1$ to $3, n=115$ ) for the vignette directed at the fictitious patient with depression and self-harm.

\section{Discussion}

\section{Main findings}

Unfortunately, only a very small proportion (2\%) of people returned the unsolicited leaflet even though they had a £4 incentive to do so. The results indicate that the majority of unsolicited leaflets were disregarded and are unlikely to be effective unless other methods are used to encourage members of the public to engage in the campaign. By contrast, the leaflet was read by almost a third of the research panel. Furthermore, it made no difference at what point the return-to-sender instructions were included suggesting that most panel participants read the entire 700 word leaflet. The majority of the sample was White British so the results do not indicate the views of ethnic minority people and other stigmatised groups. It may be helpful to assess the view of these people in separate projects.

The unsolicited leaflet had an additional line along one lower border offering participants $£ 4$ if they returned the leaflet in the accompanying freepost envelope. The instructions were clearly visible in the same sized text as the remainder of the leaflet. However, the instructions were highlighted by being placed along the lower border. There was a significant incentive to respond to the leaflet, although some people may have read the leaflet yet chose not to claim the reimbursement. Nevertheless, members of the research panel were 15 times more likely to return the leaflet than members of the general public. Hence, it is likely that only a small proportion of unsolicited leaflets were read. This suggests that the leaflet would achieve little effect on members of the general public unless people were previously sensitised to engage in the campaign.

An important question concerns why two-thirds of the research panel did not respond. This is a highly relevant issue for many aspects of medical research. However, this is a new research question and it is an issue for further research. Unfortunately, there were no anecdotal reports or feedback evidence as to why these people did not respond. It is likely that they simply did not read the modified leaflet or they failed to notice the return-to-sender statement contained within it.

The panel members were from households widely separated and they were not likely to be in contact with each other. However, members of the research panel had 
previously taken part in similar projects and they presumably had an interest in this form of questionnaire research. They were also familiar with the system of payment of $£ 4$ and would be expecting to read the entire leaflet and questionnaire. Although the researchers could have attempted to contact the majority of respondents who failed to respond, it seems unlikely that they would respond to any further enquiries, having ignored the initial approach. It is likely that people who failed to respond may have done so to avoid being sent junk mail or similar direct mail marketing. Furthermore, many people in Britain are saturated with direct marketing in leaflets and newspapers. Consequently, they are likely to ignore all unsolicited mail.

Reading the leaflet was not required as part of the second study. Nevertheless, almost a third of the sample (29\%; 115 out of 400 ) actually read the leaflet. This included $61.5 \%$ of those who completed the questionnaire (115 out of 187). Between 27 and $30 \%$ of participants returned the leaflet as instructed regardless of whether the return-tosender statement was at the start or end of the leaflet. It is therefore encouraging to report that participants seemed to read the entire 700 word leaflet. This is indicated by the fact that the position of the concealed return-to-sender statement in the leaflet was irrelevant.

Direct promotional mail shots are often read by fewer than $10 \%$ of recipients. ${ }^{20,21}$ Furthermore, the Direct Marking Association analysed 1122 industry-specific campaigns and determined that the average response rate for direct mail was $2.61 \% .^{22,23}$

Just over half of the respondents from the research panel correctly reported that one in four people will be affected by a mental illness. This statistic was the same in the group who returned the leaflet and those who did not. This compares with $16 \%$ of the general public in England. ${ }^{15}$ Of note, only $20 \%$ of participants from the original research panel correctly endorsed the one in four proportion during previous research. ${ }^{24}$ These results suggest that the 400member research panel was atypical and unusually wellinformed about mental illness. It was not an objective of the study to determine whether the Time to Change leaflet had an effect on stigmatised attitudes. However, an incidental finding was that those participants from the research panel who returned the leaflet did not have a more positive attitude towards mental illness than members of the general public. The mean stigma score using AMIQ was +1.00 for the 115 members of the research panel (s.d. $=0.22)$ compared with a mean score of +2.35 (s.e.=0.10) from 1098 members of the UK general public. ${ }^{17}$

There are now many suggested means of reducing the stigma of mental illness including recommendations in Action on Mental Health - A Guide to Promoting Social Inclusion $^{11}$ and the English Time to Change campaign (www.time-to-change.org.uk). Unfortunately, responses tend to be small, especially if negative consequences of mental illness are also disseminated. ${ }^{25}$ Knox et $a l^{26}$ showed that addressing stigmatised attitudes to mental illness among 4 million members of the US armed forces with mandatory training to recognise mental illness significantly reduced suicide rates but not stigmatised attitudes. Moreover, it was possible in this setting to insist on engagement in anti-stigma training, whereas involvement of the general public is entirely voluntary. One of the main barriers to the success of any public campaign (whether directed for the benefit of the public or promoting any product) is engaging the target audience $\mathrm{e}^{20,21}$ - the public are saturated with promotional material and attempting to catch the attention of the population is notoriously difficult. In this respect the Time to Change leaflet is likely to have a minimal impact unless other methods (possibly television advertising campaigns) had been made to encourage members of the public to read it.

Overall, the leaflet achieved a relatively high impact in the research panel sample compared with typical results from other direct marketing campaigns, with at least $29 \%$ of participants reading the leaflet (many of them apparently read the entire 700-word leaflet). This is very encouraging, although the sample was likely to be unusually motivated. However, the low response rate $(2 \%)$ to the unsolicited leaflet suggests that the leaflet is likely to have a minimal impact unless other methods had been made to engage the target population such as motivational interviewing or attendance at meetings to highlight mental illness.

The main result is that a pre-selected panel had a much higher response rate (29\%) than members of the general public (2\%). The results from the research panel suggest that the leaflet has some beneficial effects, at least in this rather biased sample. Hence, the leaflet seems reasonably well designed. However, the overall conclusion is that the leaflet has been ignored by the vast majority of people and it would take a huge effort to gain the attention of a significant proportion of the public using these postal leaflets.

\section{Strengths and limitations}

It is possible that a significant proportion of respondents read the leaflet but did not return it. However, this is likely to affect participants from both the research panel and those from the general public. Members of the research panel were 15 times more likely to return the leaflet than members of the general public. Hence, it is likely that only a small proportion of unsolicited leaflets were read.

The survey involved follow-up of participants recruited for a previous trial who were unusually well informed about mental illness (over half were aware that one in four people are likely to develop a mental illness). There was an excess of older respondents, although the gender and employment status of participants were reasonably matched to that from UK census surveys. However, the panel was unavoidably self-selecting and may not generalise across the whole population. Ideally, interviews could be conducted using a quota survey of households with repeat visits for nonresponders. ${ }^{5}$ Unfortunately, this is prohibitively expensive and is still likely to produce atypical samples.

\section{Funding}

All funding was provided by the authors.

\section{About the authors}

Dr Vania Mendes BSc is a student psychologist at the Institute of Psychiatry, London. Dr Joby Maducolil Easow MBBS is a registrar in psychiatry at the South Essex Partnership NHS Trust, Southend on Sea, 
Essex. Dr Jason Luty PhD MRCPsych is a consultant in addictions psychiatry at South Essex Partnership NHS Trust, Southend on Sea and also an honorary consultant in addictions psychiatry at Cambridge \& Peterborough Mental Health NHS Trust, Cambridge.

\section{References}

1 Biernat M, Dovidio JF. Stigma and stereotypes. In The Social Psychology of Stigma (eds TF Heatherton, RE Kleck, MR Hebl): 88-125. Guilford Press, 2000

2 Corrigan $\mathrm{P}$, Markowitz FE, Watson A, Rowan D, Kubiak MA. An attribution model of public discrimination towards people with mental illness. J Health Soc Behav 2003; 44: 162-79.

3 Appleby L. Safer Services. Department of Health, 1999.

4 Granello D, Pauley PS, Carmichael A. Relationship of the media to attitudes towards people with mental illness. J Humanist Couns Educ Develop 1999; 38: 89-110.

5 Crisp AH, Gelder M, Goddard E Meltzer H. Stigmatization of people with mental illness: a follow-up study within the Changing Minds campaign of the Royal College of Psychiatrists. World Psychiatry 2005; 4: $106-34$

6 Penn DL, Guynan K, Daily T, Spaulding WD, Garbin P, Sullivan M. Dispelling the stigma of schizophrenia. Schizophr Bull 1994; 20: 567-77.

7 Thornton JA, Wahl OF. Impact of newspaper articles on attitudes towards mental illness. J Community Psychol 1996; 24: 17-21.

8 Mayville E, Penn DL. Changing societal attitudes towards persons with severe mental illness. Cogn Behav Pract 1998; 5: 241-53.

9 Penn DL, Martin J. The stigma of severe mental illness. Some potential solutions for a recalcitrant problem. Psychiatr Q 1998; 69: 235-47.

10 Corrigan PW, Penn DL. Lessons from social psychology on discrediting psychiatric stigma. Am Psychol 1999; 54: 765-76.

11 Office of the Deputy Prime Minister. Action on Mental Health - A Guide to Promoting Social Inclusion. Office of the Deputy Prime Minister, 2004 (http://www.socialinclusion.org.uk/publications/Action_on_Mental_ Health\%20Fact_Sheets.pdf).

12 Paykel ES, Hart D, Priest RG. Changes in public attitudes to depression during the Defeat Depression Campaign. Br J Psychiatry 1998; 173 519-22.
13 Luty J, Umoh O, Sessay M, Sarkhel A. Effectiveness of Changing Minds campaign factsheets in reducing stigmatised attitudes towards mental illness. Psychiatr Bull 2007; 31: 377-81.

14 Mehta N, Kassam A, Leese M, Butler G, Thornicroft G. Public attitudes towards people with mental illness in England and Scotland, 19942003. Br J Psychiatry 2009; 194: 278-84.

15 Prior G. Attitudes to Mental Illness 2010. TNS-BMRB Office of National Statistics, 2010

16 Time to Change. Let's end mental health discrimination (leaflet). Available from the author

17 Luty J, Fakuda D, Umoh O, Gallagher J. Validation of a short instrument to measure stigmatised attitudes towards mental illness. Psychiatr Bull 2006; 30: 257-60.

18 Cunningham JA, Sobell LC, Chow VMC. What's in a label? The effects of substance types and labels on treatment considerations and stigma. J Stud Alcohol 1993; 54: 693-9.

19 Luty JS, Kumar P, Stagias K. Stigmatised attitudes in independent pharmacies associated with discrimination towards individuals with opioid dependence. Psychiatrist 2010; 34: 511-4.

20 Oppenheim AN (1992) Questionnaire Design, Interviewing and Attitude Measurement (2nd edn). Continuum Publishers, 1992.

21 Royal Mail. Average Advertising Direct Mail Response Rates. Royal Mail, 2010 (http://www.directmailroi.co.uk).

22 Robson J. The direct route to beating recession: selling on the doorstep and through parties is resolutely profitable. The Independent 1992; 8 September (http://www.independent.co.uk/news/business/the-directroute-to-beating-recession-selling-on-the-doorstep-and-throughparties-is-resolutely-profitable-janet-robson-finds-1550147.html)

23 Direct Marketing Association. Response Rates for Industry-Specific Direct Marketing Campaigns. Direct Marketing Association, 2010 (http:// www.gaebler.com/Direct-Mail-Response-Rates.htm).

24 Abraham A, Easow JM, Ravichandren P, Mushtaq S, Butterworth L, Luty JS. Effectiveness and confusion of the Time to Change anti-stigma campaign. Psychiatrist 2010; 34: 230-3.

25 Penn DL, Chamberlin C, Mueser KT. The effects of a documentary film about schizophrenia on psychiatric stigma. Schizophr Bull 2003; 29: 383-91.

26 Knox T, Smith J, Hereby H. Risk of suicide and related adverse outcomes after exposure to a suicide prevention programme in the US air force: cohort study. BMJ 2003; 327: 1376-8. 